\title{
The revelation effect for item and associative recognition: Familiarity versus recollection
}

\author{
TERRI E. CAMERON and WILLIAM E. HOCKLEY \\ Wilfrid Laurier University, Waterloo, Ontario, Canada
}

\begin{abstract}
The revelation effect occurs when items on a recognition test are more likely to be judged as being old if they are preceded by a cognitive task that involves the processing of similar types of stimuli. This effect was examined for item (single-word) and associative (word-pair) recognition. We found, in Experiments 1 and 2, a revelation effect for item, but not for associative recognition under normal study conditions. A revelation effect for both item and associative recognition was observed in Experiments 3 and 4 when study time was extremely brief, thus limiting the encoding of information that would support recall or recollection. In Experiment 5, we demonstrated that the revelation effect for item recognition is eliminated when item recognition decisions are made in the context of a study item. The results show that the revelation task influenced recognition decisions based on familiarity, but not decisions that involved recall or recollection.
\end{abstract}

In studies of recognition memory, subjects are more likely to say that a probe word has been on a previously studied list if the probe is preceded by a verbal cognitive task. This result is found both for items that were on the original study list (targets), and for items that were not (lures). This effect has turned out to be quite puzzling, both because of its generality, and because it is not predicted or easily explained by current theories of recognition memory.

\section{The Revelation Effect}

Watkins and Peynircioğlu (1990) were the first to investigate what they termed the revelation effect, following their earlier, serendipitous discovery of this phenomenon (Peynircioğlu \& Watkins, 1988). They showed that this effect can be produced by revealing the test word one letter at a time, or as an anagram, or by rotating the individual letters of the word, or the word as a whole, by varying degrees. Watkins and Peynircioğlu also showed that the revelation effect appears to influence only episodic memory judgments, because they observed no such effect in tasks involving semantic memory decisions.

Frigo, Reas, and LeCompte (1999) showed further that it is the subjects' belief that they are drawing on a memory of a past event, and not the actual memory for the past event, that is important for the revelation effect to occur. Their subjects listened to radio static, which they were told contained a subliminal word list, although no words

This study was supported by an operating grant from the Natural Sciences and Engineering Research Council of Canada to the second author. Experiments 1, 2, and 3 were carried out by the first author for her honors thesis (Cameron, 1998). We thank Marty Niewiadomski for running Experiments 4 and 5, Bruce Whittlesea and K. G. White for their constructive reviews, and Robert Greene for several comments and suggestions that greatly improved this paper. Correspondence can be addressed to W. E. Hockley, Department of Psychology, Wilfrid Laurier University, Waterloo, ON, N2L 3C5 Canada (e-mail: whockley@wlu.ca). were actually presented. At test, the subjects were asked to use their intuition to guess or imagine the words that were on the study list. Although there was no actual study list for the subjects to refer back to, a revelation effect still occurred. Therefore, it appears that a necessary condition for the revelation effect is that subjects believe that they are making an episodic judgment based upon a specific experience. The episodic judgment is not limited to recognition decisions; the revelation effect has also been found for judgments of item frequency and list discrimination (Westerman \& Greene, 1996).

Several studies have further demonstrated the robustness and generality of the revelation effect and also have ruled out a number of explanations of the phenomenon. The revelation effect has been shown not to be due to the extra time or effort devoted to the distorted test items (Luo, 1993; Peynircioğlu \& Tekcan, 1993). The revelation effect is also not dependent on subjects' successfully solving the revelation task, so it cannot be the result of subjects' adopting more liberal recognition decision criteria because they have successfully completed a mental task (Westerman \& Greene, 1998). The fact that the revelation effect can be observed for "no" responses (Westerman \& Greene, 1996, Experiment 4), or when subjects are instructed to respond "yes" to new items (Westerman \& Greene, 1996, Experiment 5) shows that the effect is not due to a simple bias to respond positively. Westerman and Greene (1998) also showed that the task that precedes the test probe must be compatible with the type of information used for the recognition decision. As an example, the revelation effect occurs for number lists when mathematical formulas are used, but does not occur if words are preceded by mathematical formulas. This result eliminates divided attention or switches of attention as an explanation of the revelation effect.

Early accounts of the revelation effect were based on the assumption that the revelation task, in some way, aug- 
ments or increases the familiarity (LeCompte, 1995) or fluency (Luo, 1993) associated with the test probe. Westerman and Greene (1996, Experiment 7), however, also found a revelation effect when the revelation task was based on a word that was unrelated to the recognition test probe. For example, subjects were more likely to give a positive response to the test probe VINEYARD after solving an anagram for RAINDROP. Cameron (1998, Experiment 1) showed further that the size of revelation effect was statistically equivalent when the anagram was the same as the probe item and when the anagram was an unrelated word. Westerman and Greene (1998) went on to demonstrate that a revelation effect occurred when the recognition judgment was preceded by memory span tests, letter counting tasks, synonym search tasks, and the rearranging of meaningless strings of letters. These surprising results indicate that the revelation effect is not due to revelation per se, and cannot be due, in any straightforward way, to an increase in familiarity that arises from priming or fluency.

Westerman and Greene (1998) suggested an account of the revelation effect based on principles common to global-matching models of memory (e.g., the models of Gillund \& Shiffrin, 1984; Hintzman, 1988; Murdock, 1993). The central assumption of these models is that recognition judgments are based on the match or overall similarity between the representation of the probe item and the contents of episodic memory. Westerman and Greene make the further assumption that the revelation task activates additional information in memory that is not activated by the presentation of the test item itself. This additional activation persists for a short time, so that when the recognition item is encoded, the memory activation it produces is added to the activation produced by the revelation task. Thus, the higher overall activation in the revelation condition makes the recognition test item seem more familiar.

More recently, Hicks and Marsh (1998) proposed a decision criterion shift account of the revelation effect. Hicks and Marsh argued that the revelation task temporarily activates competing alternatives in memory. The competing alternatives serve to reduce the signal-tonoise ratio for the probe item being judged as old or new. Faced with a more difficult discrimination task, the subjects adopted a more liberal decision criterion, thereby increasing the hit and false alarm rates for the probe item in the revelation condition.

Both of the explanations above involve the assumption that the revelation task influences memory decisions that are primarily based on an assessment or evaluation of the familiarity of the test probe. Support for this assumption would be provided by the demonstration that the revelation effect does not occur for memory decisions that are based more on a recall or recollective retrieval process than on familiarity. A number of researchers have argued that associative recognition is one such task.

\section{Associative Recognition}

In the typical associative recognition procedure, the subjects study pairs of words with instructions to form a relation between the words of each pair so that they will be able to remember which words were presented together. Associative recognition involves discriminating between same or old test pairs and rearranged or new test pairs. Rearranged test pairs consist of two words that have appeared in different pairs at study. Because the two words in both the same and rearranged test pairs are studied words, the subjects cannot use the familiarity of the individual words to discriminate between old and new word pairs. Rather, they must base their recognition decisions on their memories for the associations formed between the words of the pairs at study.

Humphreys (1978; Bain \& Humphreys, 1988) and Clark (1992; Clark \& Burchett, 1994; Clark \& Hori, 1995; Clark, Hori, \& Callan, 1993; see Clark \& Gronlund, 1996 , for a recent review) have suggested that associative recognition decisions are based, at least in part, on a recall-like retrieval process. That is, the discrimination between a studied test pair, $\mathrm{A}-\mathrm{B}$, and a rearranged test pair, $\mathrm{A}-\mathrm{C}$, could be made by recalling the item that was paired with A at study.

Several different findings provide support for this view of associative recognition. For example, it is well established that low-frequency words are recognized more accurately than high-frequency words, whereas high-frequency words are generally recalled better than low-frequency words (see Gillund \& Shiffrin, 1984, for a review). Tests of word frequency for associative recognition have shown no effects of word frequency (Hockley, 1994), or an advantage for high-frequency words (Clark, 1992; Clark \& Shiffrin, 1992). Thus, the associative recognition results are more consistent with the word frequency effects found for recall than for recognition. In addition, as Rotello and Heit (in press) have argued, the effects of study instruction on associative recognition are more similar to the effects of instruction on recall than they are to the effects of instruction on item recognition. Instructions to form associations between word pairs improves associative recognition performance without influencing item recognition (Hockley \& Cristi, 1996), just as the expectation of a recall test improves recall performance but does not affect item recognition (May \& Sande, 1982). Yonelinas (1997) has argued that associative recognition is primarily based on recollection, whereas item recognition is based to a greater extent on familiarity on the basis of analyses of receiver-operating characteristics in the two tasks. Hockley and Consoli (1999), who used the remember/know response procedure, have shown that associative recognition decisions are identified as remember responses (i.e., responses that are based on the recollection of specific details of the prior experience) to a significantly greater extent than are item recognition decisions. Finally, Rotello and Heit (in press) used a re- 
sponse signal procedure to provide evidence for a recallto-reject process in associative recognition that is not found for item recognition.

\section{Familiarity Versus Recollection}

In Experiments 1 and 2, the subjects studied pairs of words, and their recognition memory for both item and associative information was tested. Half of the recognition tests were preceded by an anagram task for an unrelated word. If the revelation effect influences only familiaritybased recognition decisions, and item recognition is based on familiarity to a greater extent than is associative recognition, then the revelation effect should be much greater for item recognition than for associative recognition. Experiment 2 was a replication of Experiment 1. Because these experiments differed only with regard to the study presentation rate, they are reported together.

\section{EXPERIMENTS 1 AND 2}

\section{Method}

Subjects. Fifty-six students participated for course credit in Experiment 1, and 36 participated in Experiment 2.

Apparatus and Stimuli. The study and test list words were randomly selected from a pool of 480 concrete nouns derived from Paivio, Yuille, and Madigan (1968). All words had an imageability rating of 5.00 or above according to the Paivio et al. norms, which rate words from 1 to 7 . The anagrams were a set of 140 eight-letter words selected from Gibson and Watkins (1988). All anagrams were scrambled in the same order, so that all could be solved in the same manner. The solution order for every anagram was 54687321 (i.e., forensic would appear as nescirof).

The stimulus presentation and response recording were controlled by computers. The subjects used the " $z$ " key for "yes" (i.e., old) responses; the "/" key for "no" (i.e., new) responses; and the " $y$ " key for indicating that they had solved the anagram. The computer keyboard was covered by an opaque cover that left only the labeled response keys exposed. When solving the anagrams, the subjects said their responses into a microphone attached to a tape recorder.

Procedure. The subjects viewed a study list of 90 random word pairs presented in the center of the computer screen. The first and last five pairs were buffers and were not tested. In Experiment 1, word pairs were presented for $2.5 \mathrm{sec}$, and in Experiment 2, they were presented for $3.5 \mathrm{sec}$. There was a 0.5 -sec blank interval between presentations in both experiments. The subjects were asked to remember the word pairs by making associations, such as by imagining the two words together in a mental picture, or by making up a sentence that included both words.

The recognition test consisted of 80 probes; 40 were targets, and 40 were lures. Half of the targets and lures were single-word (item recognition) tests, and half of the targets and lures were word-pair (associative recognition) tests. For target item test trials, half were words presented as the right-hand member of a study pair, and half were words presented as the left-hand member of a study pair. For the associative recognition trials, targets were two words presented together at study. Lures were rearranged test pairs that were formed by pairing the left member of one study pair with the right member of a different study pair (thus preserving the left-right study presentation order of the individual words).

Two target items, two target pairs, and two rearranged pairs were taken from each consecutive block of eight study presentations (excluding the buffer presentations). One of each test presentation (including lure item trials) was presented intact, or normally, in the test, and one of each test presentation was preceded by an unrelated anagram. Recognition test probes were presented in the center of the computer screen flanked on either side by a question mark. "Old" appeared in the bottom left and "new" appeared in the bottom right of the screen as a reminder of the recognition task and the response keys. The order of test presentations was arranged randomly for each subject.

The subjects were given test instructions following the presentation of the study list. They were asked to respond "yes" to single words that were on the study list, and to same pairs that appeared together on the study list, and to respond "no" to new single words and to rearranged word pairs. They were also told that the recognition test included some words presented in anagram form. The subjects were given the solution code for the anagrams (which also appeared on the computer screen under every anagram), and were asked to say their answers to the anagrams into a microphone, and then to press the response key to indicate that they had solved the anagram. The statement "press the Y key when solved" also appeared below the anagram on the screen. All aspects of the test were self-paced, with a 1-sec blank interval between presentations.

\section{Results and Discussion}

The mean proportion of old responses for item and associative recognition in the intact and revelation test conditions are presented in Table 1. The proportions of old responses were analyzed in a 2 (item vs. associative recognition) $\times 2$ (intact vs. anagram test condition) $\times 2$ (old vs. new test probe) analysis of variance (ANOVA).

In Experiment 1, overall performance for item and associative recognition did not differ reliably $[F(1,55)=$ $\left.2.33, M S_{\mathrm{e}}=.065\right]$. As expected, hit rates were greater than false alarm rates $\left[F(1,55)=211.8, M S_{\mathrm{e}}=.074\right]$. The main effect of test condition was significant $[F(1,55)=$ $6.76, M S_{\mathrm{e}}=.039$ ], but was qualified by an interaction with type of recognition test $\left[F(1,55)=6.75, M S_{\mathrm{e}}=\right.$ $.021]$. No other interactions approached significance (all $F \mathrm{~s}<1$ ).

To explore the recognition test $\times$ test condition interaction, the results for each recognition test were analyzed separately. For item recognition, the main effects of type of test probe $\left[F(1,55)=158.3, M S_{\mathrm{e}}=.046\right]$ and test condition $\left[F(1,55)=14.43, M S_{\mathrm{e}}=.027\right]$ were highly reliable. These variables did not interact $[F(1,55)<1]$. For associative recognition, only the effect of old versus new test probe was reliable $\left[F(1,55)=157.5, M S_{\mathrm{e}}=.053\right]$. The effect of test condition $[F(1,55)<1]$ and the interaction between test probe and test condition $[F(1,55)<1]$ did not

Table 1

Proportion of Old Responses for Item and Associative Recognition to Old and New Test Probes for the Intact and Anagram Test Conditions of Experiments 1 and 2

\begin{tabular}{lccccc}
\hline & \multicolumn{2}{c}{ Item Recognition } & & \multicolumn{2}{c}{ Associative Recognition } \\
\cline { 2 - 3 } \cline { 5 - 6 } & Old & New & & Old & New \\
\hline Experiment 1 & & & & .64 & .24 \\
$\quad$ Intact & .62 & .26 & & .64 & .26 \\
$\quad$ Anagram & .70 & .35 & & & \\
Experiment 2 & & & .71 & .19 \\
$\quad$ Intact & .66 & .19 & & .68 & .23 \\
$\quad$ Anagram & .69 & .36 & & .023
\end{tabular}

Note-Standard errors of the means vary from .023 to .033 in Experiment 1 and .030 to .040 in Experiment 2 . 
approach significance. Thus, a revelation effect was found for item recognition but not for associative recognition.

The pattern of results for Experiment 2 was similar to that of Experiment 1, although, as expected, both item and associative recognition performance were somewhat more accurate owing to the slower study presentation rate. As in Experiment 1, overall item recognition performance and associative recognition performance were comparable $[F(1,35)<1]$, and hit rates were greater than false alarm rates $\left[F(1,35)=129.48, M S_{\mathrm{e}}=.109\right]$. Once again, the main effect of test condition was reliable $\left[F(1,35)=6.61, M S_{\mathrm{e}}=.028\right]$, but was qualified by a significant interaction with type of recognition test $\left[F(1,35)=6.99, M S_{\mathrm{e}}=.025\right]$. Unlike in Experiment 1 , the interaction between test condition and test probe $\left[F(1,35)=10.41, M S_{\mathrm{e}}=.022\right]$ was also significant. As in Experiment 1, the interactions between type of recognition test and test probe $\left[F(1,35)=3.76, M S_{\mathrm{e}}=.037\right]$ and recognition test $\times$ test probe $\times$ test condition $[F(1,35)<1]$ were not significant.

An analysis of item recognition revealed that the effects of test probe $\left[F(1,35)=96.2, M S_{\mathrm{e}}=.060\right]$ and test condition $\left[F(1,35)=11.02, M S_{\mathrm{e}}=.033\right]$ and their interaction $\left[F(1,35)=9.42, M S_{\mathrm{e}}=.020\right]$ were reliable. This interaction indicates that the revelation effect was greater for false alarms than for hits. As in Experiment 1, the corresponding analysis of associative recognition showed only a main effect of test probe $\left[F(1,35)=98.51, M S_{\mathrm{e}}=\right.$ $.087]$. The main effect of test condition $[F(1,35)<1]$ and the interaction between test condition and test probe $\left[F(1,35)=2.58, M S_{\mathrm{e}}=.023\right]$ were not reliable.

To further contrast the difference between item and associative recognition performance, $A^{\prime}$ estimates of discriminability and $B_{\mathrm{D}}^{\prime \prime}$ estimates of criterion placement were calculated. ${ }^{1}$ The mean estimates for item and associative recognition for each test condition are given in Table 2. In Experiment 1, the $A^{\prime}$ estimates for item recognition did not differ significantly between the test conditions $[t(55)=0.546]$, whereas the mean criterion estimate for intact recognition decisions was significantly more conservative than for decisions following anagrams $[t(55)=3.302]$. In contrast, for associative recognition the corresponding estimates of both $A^{\prime}[t(55)=0.195]$ and $B_{\mathrm{D}}^{\prime \prime}[t(55)=1.085]$ did not reliably differ. In Experiment 2 , the mean estimates of both $A^{\prime}[t(35)=3.089]$

Table 2

Mean Estimates of $A^{\prime}$ and $B_{\mathrm{D}}^{\prime \prime}$ for

Item and Associative Recognition in the

Intact and Anagram Test Conditions of Experiments 1 and 2

\begin{tabular}{lrrrrr}
\hline & \multicolumn{2}{c}{ Item Recognition } & & \multicolumn{2}{c}{ Associative Recognition } \\
\cline { 2 - 3 } \cline { 5 - 6 } & $A^{\prime}$ & \multicolumn{1}{c}{$B_{\mathrm{D}}^{\prime \prime}$} & & $A^{\prime}$ & $B_{\mathrm{D}}^{\prime \prime}$ \\
\hline Experiment 1 & & & & \\
$\quad$ Intact & .754 & .201 & & .769 & .305 \\
$\quad$ Anagram & .742 & -.126 & & .765 & .188 \\
Experiment 2 & & & & \\
$\quad$ Intact & .811 & .328 & & .825 & .223 \\
Anagram & .716 & -.035 & & .787 & .184 \\
\hline
\end{tabular}

and $B_{\mathrm{D}}^{\prime \prime}[t(35)=2.634]$ for item recognition differed reliably between the intact and anagram test conditions. For associative recognition, once again the differences in $A^{\prime}[t(35)=1.198]$ and $B_{\mathrm{D}}^{\prime \prime}[t(35)=0.321]$ did not approach significance.

The results of both Experiments 1 and 2 show that item recognition decisions are susceptible to the influence of the revelation task, but that recognition decisions for associative recognition are not. These results are consistent with the view that item recognition is largely based on familiarity, whereas associative recognition decisions are based more on recall or recollection, and that the revelation effect only influences familiarity-based decisions. If the familiarity-based interpretation of the revelation effect is correct, it should be possible to find the revelation effect for associative recognition if pair recognition responses are based more on familiarity than on recall. This could be the case if conditions at study are such as to reduce the opportunity to encode the information that supports recall, so that associative recognition must be based more on familiarity, as is item recognition. We conducted Experiment 3 to see whether a revelation effect would occur for associative recognition in such a situation.

\section{EXPERIMENT 3}

In Experiment 3, study time was drastically reduced in order to minimize the encoding of information that would support a recall process for associative recognition. If a revelation effect for associative recognition should be found under these conditions, it would provide further support for the view that the revelation task influences recognition decisions based on familiarity, but not decisions based on recall or recollection.

\section{Method}

Subjects. Eighty first-year university students participated for course credit.

Apparatus and Stimuli. The stimuli and apparatus were identical to those of Experiments 1 and 2.

Procedure. The procedure was identical to those of Experiments 1 and 2, except that the study presentation time was shortened to $0.5 \mathrm{sec}$ per pair. Before beginning the study phase, the subjects were informed of the fast presentation rate, but were told that memory for the word pairs would still be possible.

\section{Results and Discussion}

The mean proportions of old responses for each type of test and test condition are summarized in Table 3 . All statistical analyses were identical to those performed in Experiments 1 and 2. Overall performance for item and associative recognition did not differ reliably $[F(1,79)=$ $\left.3.82, M S_{\mathrm{e}}=.077\right]$. As expected, overall performance was poorer in Experiment 3 than in Experiments 1 and 2, as hit rates were lower and false alarm rates were higher. Nevertheless, hit rates were still reliably greater than false alarm rates $\left[F(1,79)=56.02, M S_{\mathrm{e}}=.109\right]$. The main effect of test condition, demonstrating the revelation effect, was highly significant $\left[F(1,79)=56.02, M S_{\mathrm{e}}=\right.$ 
Table 3

Proportion of Old Responses for Item and Associative Recognition to Old and New Test Probes for the Intact and Anagram Test Conditions of Experiment 3

\begin{tabular}{lccccc}
\hline & \multicolumn{2}{c}{ Item Recognition } & & \multicolumn{2}{c}{ Associative Recognition } \\
\cline { 2 - 3 } \cline { 5 - 6 } & Old & New & & Old & New \\
\hline Intact & .53 & .39 & & .50 & .38 \\
Anagram & .64 & .49 & & .53 & .47 \\
\hline
\end{tabular}

Note-Standard errors of the means vary from .021 to .025 .

.109]. Unlike in Experiments 1 and 2, the interaction between test condition and type of recognition test was not reliable $\left[F(1,79)=3.08, M S_{\mathrm{e}}=.026\right]$. The interactions of recognition test $\times$ test probe $\left[F(1,79)=3.55, M S_{\mathrm{e}}=\right.$ $.026]$, test condition $\times$ test probe $\left[F(1,79)<1, M S_{\mathrm{e}}=\right.$ $.025]$, and recognition test $\times$ test condition $\times$ test probe $\left[F(1,79)=1.74, M S_{\mathrm{e}}=.024\right]$ were also not significant.

To confirm that the revelation effect was reliable for both tests of item and associative recognition, separate analyses were performed for each type of test. For item recognition, the main effects for test condition $[F(1,79)=$ $\left.28.85, M S_{\mathrm{e}}=.031\right]$ and probe type $[F(1,79)=48.02$, $\left.M S_{\mathrm{e}}=.033\right]$ were significant, whereas the interaction between these variables was not $[F(1,79)<1]$. The same statistical pattern was found for associative recognition; test condition $\left[F(1,79)=11.04, M S_{\mathrm{e}}=.027\right]$ and test probe $\left[F(1,79)=21.26, M S_{\mathrm{e}}=.032\right]$ were significant and their interaction was not reliable $\left[F(1,79)=1.69, M S_{\mathrm{e}}=.028\right]$.

Analyses of the estimates of $A^{\prime}$ for item recognition revealed that discrimination in the intact condition (.598) did not differ from the anagram condition $(.619)[t(79)=$ .809], whereas the criterion estimate for intact tests (.144) was significantly greater than that for tests preceded by anagrams $(-.219)$. For associative recognition, the difference in $A^{\prime}$ favoring the intact condition (.594) over the anagram condition $(.547)$ was not reliable $[t(79)=1.06]$, but, like item recognition, the criterion estimate for the intact condition (.208) was significantly greater than that for the revelation condition $(-.012)[t(79)=3.613]$.

In Experiments 1 and 2, a revelation effect was found for item recognition but not for associative recognition under normal study conditions. When presentation time at study was drastically reduced in Experiment 3, which lowered overall discrimination performance for both item and associative recognition, a significant revelation effect was observed for both item and associative recognition. The revelation effect for item recognition does not appear to be dependent on the level of accuracy. In contrast, a revelation effect for associative recognition emerges when discrimination performance is relatively poor. Experiment 4 was designed to replicate the results of Experiment 3 with an even more extreme reduction in study time.

\section{EXPERIMENT 4}

In Experiment 4, the presentation time of the study pairs was very brief and the pairs were followed by a pat- tern mask. This allowed the subjects to read, at best, only one of the two presented words. As a consequence, the subjects were unable to encode any associative information that would support associative recognition decisions. Experiment 4, then, represents the associative recognition analogue of Frigo et al.'s (1999) demonstration of the revelation effect for item recognition using a sham study list.

\section{Method}

Subjects. Sixty-six undergraduate students participated for course credit.

Apparatus and Stimuli. The stimuli and apparatus were identical to those of Experiment 3.

Procedure. The procedure was identical to that of Experiment 3, except that the study presentation time was reduced to $0.1 \mathrm{sec}$ per pair. The presentation of each word of the study pair was immediately replaced by a set of Xs for $0.75 \mathrm{sec}$. A blank interval lasting $0.5 \mathrm{sec}$ intervened before the presentation of the next study pair. Before beginning the study phase, the subjects were warned of the very fast presentation rate, but they were instructed to pay close attention to the stimulus displays and to read as many words as possible. They were also led to believe that they would be able to remember more words than they actually read. At test, the subjects were told that when they were unsure of what decision to make, they should simply make their best guess without being concerned about making mistakes.

\section{Results and Discussion}

The mean proportions of old responses in each condition are summarized in Table 4. Because the purpose of Experiment 4 was to determine whether the revelation effect occurred for both item and associative recognition, each recognition test was analyzed separately. For item recognition, hit rates were reliably greater than false alarm rates $\left[F(1,65)=29.79, M S_{\mathrm{e}}=.034\right]$. The main effect of the revelation manipulation was also significant $[F(1,65)=$ $\left.16.85, M S_{\mathrm{e}}=.031\right]$. The interaction between probe type and test condition did not approach significance $[F(65)<$ 1]. A comparison of estimates of $A^{\prime}$ showed that discrimination in the intact condition (.608) did not differ reliably from performance in the anagram condition $(.585)$ $[t(65)=.787]$. The criterion estimate was once again greater in the intact condition (.202) than in the anagram condition $(-.094)[t(65)=4.232]$.

For associative recognition, hit rates did not differ from false alarm rates $[F(1,65)<1]$, which confirms that the subjects did not encode associative information that would allow a discrimination of intact from rearranged study pairs. The main effect of test condition was highly

Table 4

Proportion of Old Responses for Item and Associative Recognition to Old and New Test Probes for the Intact and Anagram Test Conditions of Experiment 4

\begin{tabular}{lccccccc}
\hline & \multicolumn{3}{c}{ Item Recognition } & & \multicolumn{3}{c}{ Associative Recognition } \\
\cline { 2 - 4 } \cline { 6 - 8 } & Old & New & $M$ & & Old & New & $M$ \\
\hline Intact & .51 & .37 & .44 & & .51 & .54 & .53 \\
Anagram & .59 & .47 & .53 & & .62 & .57 & .60 \\
\hline
\end{tabular}

Note-Standard errors of the means vary from .023 to .030 . 
reliable $\left[F(1,65)=12.12, M S_{\mathrm{e}}=.029\right]$. The test probe $X$ test condition interaction was also statistically reliable $\left[F(1,65)=5.53, M S_{\mathrm{e}}=.018\right]$, which indicates that the revelation effect was greater for old than for new test pairs. This effect is undoubtedly spurious, since the subjects had no basis on which to discriminate between old and new test pairs. The related finding that $A^{\prime}$ was greater in the anagram condition (.541) than in the intact condition $(.474)[t(65)=2.451]$ is similarly suspect. As in item recognition, the criterion placement estimate was reliably greater in the intact condition ( -.089$)$ than in the anagram condition $(-.302)[t(65)=3.033]$.

Taken together, the results of Experiments 3 and 4 demonstrate that when the opportunity to encode associative information is severely limited or eliminated, associative recognition, like item recognition, is susceptible to the revelation effect. As the results of Experiments 1 and 2 showed, when subjects are given sufficient opportunity to form associations between random pairs of words, associative recognition is largely immune to this effect. This set of results supports the view that the revelation effect influences only recognition decisions based on familiarity. Under normal encoding conditions, associative recognition is based on a recall-like process, and is not influenced by the revelation task. However, when the information that supports the recall process is not available, associative recognition can only be based on familiarity and then becomes subject to the revelation effect. It follows that if item recognition decisions are based more on recall than on familiarity, the revelation effect for item recognition should be attenuated or eliminated. In order to determine this, we conducted Experiment 5.

\section{EXPERIMENT 5}

In this final experiment, subjects again studied random pairs of words with instructions to form associations between the two items of each pair. Study time was sufficient to allow the subjects to encode associative information. Item recognition was then tested for words presented singly and for words presented in the context of a study word. The subjects were encouraged to use the context word to help them with their item recognition decisions. It was predicted that the subjects would base their single word item recognition decisions on familiarity and again show the revelation effect. In the context condition, however, the subjects would use recall to assist their recognition decision and this would attenuate the effects of the revelation task.

\section{Method}

Subjects. Sixty-four undergraduate students participated for course credit.

Apparatus and Stimuli. The stimuli and apparatus were identical to those of the previous experiments.

Procedure. The procedure was the same as that of Experiment 1 with the following exceptions. The study presentation time was $4 \mathrm{sec}$ per pair. The test list consisted of 40 single word recognition tests and 40 tests of single words presented in the context of a study word.
Half of all tests presented old items and half presented new items. All old-item tests were left-hand members of study pairs. In the context test condition, the left word was always the target item and was underlined. All context nontarget words were always right-hand members of study pairs. Half of all test items were presented intact, and half were preceded by an unrelated anagram problem. The order of all test presentations was randomly arranged for each subject.

The subjects were instructed to make yes-no item recognition decisions, for all single test words. The subjects were given the following instructions for the word context condition:

The underlined word on the left is the test word that we ask you to decide whether or not was in the study list. The word on the right is always a word from the study list. If the word on the left is an old word, then the word on the right is the word that was presented with the old word in the study list. If the word on the left is a new word, then the word on the right was presented with a different word in the study list. Thus, the word on the right can help you to decide whether or not the test word on the left was or was not in the study list

\section{Results and Discussion}

The proportion of old responses in each test condition is presented in Table 5. An overall ANOVA based on test condition (intact vs. anagram), context condition (no context vs. context), and probe type (old vs. new) revealed the following. As was expected, hit rates were greater than false alarm rates $\left[F(1,63)=455.44, M S_{\mathrm{e}}=.086\right]$. The main effects of context $\left[F(1,63)=6.80, M S_{\mathrm{e}}=.028\right]$ and test condition $\left[F(1,63)=15.96, M S_{\mathrm{e}}=.016\right]$ were also reliable. These main effects were qualified by significant interactions between context and type of probe $\left[F(1,63)=10.64, M S_{\mathrm{e}}=.011\right]$, test condition and probe type $\left[F(1,63)=20.33, M S_{\mathrm{e}}=.022\right]$, and test condition and context $\left[F(1,63)=8.47, M S_{\mathrm{e}}=.016\right]$. The probe type $\times$ context $\times$ test condition interaction did not approach significance $[F(1,63)<1]$. Item recognition performance was more accurate in the context condition, and this advantage was greater for false alarms than for hits, and greater in the intact test condition than in the anagram test condition. The revelation effect was greater for items tested alone than for items tested in context, and greater for false alarms than for hits.

An analysis based on item recognition in the nocontext condition revealed a main effect of test probe $\left[F(1,63)=364.80, M S_{\mathrm{e}}=.043\right]$ and a main effect of the revelation manipulation $\left[F(1,63)=21.20, M S_{\mathrm{e}}=.012\right]$. The interaction between these variables was also reliable $\left[F(1,63)=4.63, M S_{\mathrm{e}}=.014\right]$; the revelation effect was greater for false alarms than for hits. The corresponding analysis for item recognition in the context condition showed a main effect of probe type $[F(1,63)=366.38$,

Table 5

Proportion of Old Item Recognition Responses to Old and New Test Probes in the No Context and Context Conditions for the Intact and Anagram Tests of Experiment 5

\begin{tabular}{lccccc}
\hline & \multicolumn{2}{c}{ No Context } & & \multicolumn{2}{c}{ Context } \\
\cline { 2 - 3 } \cline { 5 - 6 } & Old & New & & Old & New \\
\hline Intact & .74 & .21 & & .79 & .15 \\
Anagram & .78 & .32 & & .77 & .19 \\
\hline
\end{tabular}

Note-Standard errors of the means vary from .020 to .024 . 
$\left.M S_{\mathrm{e}}=.065\right]$, but no main effect of the revelation task $[F(1,63)<1]$. The interaction between probe type and test condition did reach significance $[F(1,63)=5.38$, $\left.M S_{\mathrm{e}}=.009\right]$. As can be seen in Table 5, in the context condition the hit rate was greater in the intact than in the anagram test condition, whereas the reverse was true for false alarms. The mean proportion of old responses averaged over probe type was .47 in the intact condition and .48 in the anagram condition.

For item recognition without the benefit of context, $A^{\prime}$ was greater in the intact test condition (.837) than in the anagram condition $(.807)[t(63)=2.021, p=.048]$. The mean estimate of the criterion was significantly greater in the intact condition (.116) than in the anagram condition $(-.196)[t(63)=3.356]$. For item recognition in context, discrimination was marginally greater in the intact condition (.875) than in the anagram test condition (.855) $[t(63)=1.993, p=.051]$. The difference in criterion placement between the intact (.200) and anagram (.133) test conditions, however, did not approach statistical significance $[t(63)=.695]$.

The pattern of results of Experiment 5 were as predicted. A reliable revelation effect was again observed for singleitem recognition, but this effect was virtually eliminated when item recognition decisions were made in the context of a study word.

\section{GENERAL DISCUSSION}

The present study was designed to examine the role of familiarity in the revelation effect by comparing this effect for item and associative recognition. As previously discussed, a number of investigators have argued that associative recognition is based on a recall-like, or recollection, retrieval process to a greater extent than is item recognition. It was reasoned that if the revelation task influences only familiarity-based decisions, the revelation effect would be attenuated or absent for associative recognition. This is exactly what was found in Experiments 1 and 2. As a further demonstration that the revelation task influences recognition decisions that are based on familiarity, but not on recall, study time was drastically reduced in Experiments 3 and 4 in order to decrease or eliminate the information that could be encoded to support recollection. It was thought that by reducing encoding, associative recognition would have to be based more on familiarity than on recall, as is item recognition. The results of Experiments 3 and 4 were also as predicted; a reliable revelation effect was observed for both item and associative recognition.

The familiarity-based interpretation of the revelation effect was further supported by the results of Experiment 5 . In this experiment, a revelation effect was again observed for item recognition when single words were tested. The revelation effect all but disappeared, however, when the probe word was presented in the context of a study word and when the subjects were encouraged to use the context item to aid their recognition decisions. Although item recognition for single test words was principally based on familiarity, and thus subject to the revelation effect, item recognition for words in context was based more on a recall process, and was therefore largely immune to the revelation effect.

The present findings provide strong support for accounts of the revelation effect that assume that the revelation task exerts its influence on familiarity-based decisions, but they do not distinguish between these views. The present demonstrations of the revelation effect are, for the most part, consistent with both Westerman and Greene's (1998) and Hicks and Marsh's (1998) explanations of the revelation effect. Westerman and Greene assume that the revelation task temporarily activates additional list information in memory that is not activated by the probe item itself. This additional activation increases the overall level of familiarity of both the old- and newitem distributions. If subjects adopt a relatively consistent decision criterion, the result would be an increase in both hits and false alarms for the revelation condition. Signal-detection analyses of such an effect would show a decrease in the estimate of the criterion placement with little change in discrimination. This was largely what was found in the analyses of the present findings.

In Hicks and Marsh's (1998) interpretation of the revelation effect, the preceding cognitive task temporarily activates competing alternatives, which has the consequence of reducing the signal-to-noise ratio for the test probe. In other words, the increase in familiarity caused by the revelation task has a larger impact on the newitem distribution than on the old-item distribution. To compensate, subjects adopt a more liberal decision criterion, resulting in an increase in both hits and false alarms. In this view, the reduction in the signal-to-noise ratio should also result in poorer overall discrimination performance in the revelation condition. The present results, however, provide only modest support for this prediction. Although there was a trend toward lower $A^{\prime}$ estimates for the revelation test than for the intact tests in almost all of the conditions in which a revelation effect was observed, this difference was statistically reliable only for item recognition in Experiments 2 and 5.

In summary, several different types of episodic memory decisions have been shown to be influenced by a preceding cognitive task that involves the processing of similar stimuli. The results of the present study demonstrate two important exceptions - associative recognition and item recognition performance in the context of a study word. These findings provide strong support for the view that the revelation task influences decisions based on an assessment of familiarity, but does not influence decisions that involve a recall-like or recollection retrieval process. The present results also provide a further demonstration that associative recognition decisions typically rely less on familiarity than do decisions for item recognition performed in isolation. 


\section{REFERENCES}

Bain, J. D., \& Humphreys, M. S. (1988). Relational context: Independent cues, meanings, and configurations. In G. Davis \& D. M. Thomson (Eds.), Memory in context: Context in memory (pp. 97-137). London: Wiley.

CAMERON, T. E. (1998). The revelation effect for item versus associative recognition. Unpublished honors thesis, Wilfrid Laurier University.

CLARK, S. E. (1992). Word frequency effects in associative and item recognition. Memory \& Cognition, 20, 231-243.

Clark, S. E., \& BurchetT, R. E. R. (1994). Word frequency and list composition effects in associative recognition and recall. Memory $\&$ Cognition, 22, 55-62.

Clark, S. E., \& Gronlund, S. D. (1996). Global matching models of recognition memory: How the models match the data. Psychonomic Bulletin \& Review, 3, 37-60.

ClaRK, S. E., \& Hori, A. (1995). List length and overlap effects in forcedchoice associative recognition. Memory \& Cognition, 23, 456-461.

Clark, S. E., Hori, A., \& Callan, D. E. (1993). Forced-choice associative recognition: Implications for global-matching models. Journal of Experimental Psychology: Learning, Memory, \& Cognition, $19,871-881$

Clark, S. E., \& Shiffrin, R. M. (1992). Cuing effects and associative information in recognition memory. Memory \& Cognition, 20, 580-598.

Donaldson, W. (1993). Accuracy of $d^{\prime}$ and $A^{\prime}$ as estimates of sensitivity. Bulletin of the Psychonomic Society, 31, 271-274.

Frigo, L. C., Reas, D. L., \& LeCompte, D. C. (1999). Revelation without presentation: Counterfeit study list yields robust revelation effect. Memory \& Cognition, 27, 339-343.

GiBSON, J. M., \& WATKINS, M. J. (1988). A pool of 1,086 words with unique two-letter fragments. Behavior Research Methods, Instruments, \& Computers, 20, 390-397.

GILLUND, G., \& SHIFFRIN, R. M. (1984). A retrieval model for both recognition and recall. Psychological Review, 91, 1-67.

HiCKS, J. L., \& MARSH, R. L. (1998). A decrement-to-familiarity interpretation of the revelation effect from forced-choice tests of recognition memory. Journal of Experimental Psychology: Learning, Memory, \& Cognition, 24, $1105-1120$.

HiNTZMAN, D. L. (1988). Judgments of frequency and recognition memory in a multiple-trace model. Psychological Review, 95, 528-551.

HOCKLEY, W. E. (1994). Reflections of the mirror effect for item and associative recognition. Memory \& Cognition, 22, 713-722.

HOCKLEY, W. E., \& CONSOLI, A. (1999). Familiarity and recollection in item and associative recognition. Memory \& Cognition, 27, 657-664.

Hockley, W. E., \& Cristi, C. (1996). Tests of encoding tradeoffs between item and associative information. Memory \& Cognition, 24, 202-216.

HUMPHREYS, M. S. ( 1978). Item and relational information. A case for context independent retrieval. Journal of Verbal Learning \& Verbal Behavior, 17, 175-188.

LECOMPTE, D. C. (1995). Recollective experience in the revelation ef- fect: Separating the contributions of recollection and familiarity. Memory \& Cognition, 23, 324-334.

Luo, C. R. (1993). Enhanced feeling of recognition: Effects of identifying and manipulating test items on recognition. Journal of Experimental Psychology: Learning, Memory, \& Cognition, 19, 405-413.

MAY, R. B., \& SANDE, G. N. (1982). Encoding expectancies and word frequency in recall and recognition. American Journal of Psychology, $95,485-495$.

MURDOCK, B. B. (1993). TODAM2: A model for storage and retrieval of item, associative, and serial-order information. Psychological Review, 100, 183-203.

Paivio, A., Yuille, J. C., \& Madigan, S. A. (1968). Concreteness, imagery, and meaningfulness values for 925 nouns. Journal of Experimental Psychology Monographs, 76 (1, Pt. 2), 1-25.

PeYnirCioğLU, Z. F., \& TeKCAN, A. (1993). Revelation effect: Effort or priming does not create the sense of familiarity. Journal of Experimental Psychology: Learning, Memory, \& Cognition, 19, 382-388.

PeYnircioğLU, Z. F., \& Watkins, M. J. (1988). Effect of unfolding stimulus presentation on recognition memory. In M. M. Gruneberg, P. E. Morris, \& R. Sykes (Eds.), Practical aspects of memory: Current research and issues (Vol. 2, pp. 518-523). Chichester, U.K.: Wiley.

Rotello, C. M., \& Heit, E. (in press). Associative recognition: A case of recall-to-reject processing. Journal of Memory \& Language.

Watkins, M. J., \& PeYnircioŭlu, Z. F. (1990). The revelation effect: When disguising test items induces recognition. Journal of Experimental Psychology: Learning, Memory, \& Cognition, 16, 1012-1020.

Westerman, D. L., \& Greene, R. L. (1996). On the generality of the revelation effect. Journal of Experimental Psychology: Learning, Memory, \& Cognition, 22, 1147-1153.

Westerman, D. L., \& Greene, R. L. (1998). The revelation that the revelation effect is not due to revelation. Journal of Experimental Psychology: Learning, Memory, \& Cognition, 24, 377-386.

YoNELINAS, A. P. (1997). Recognition memory ROCs for item and associative information: The contribution of recollection and familiarity. Memory \& Cognition, 25, 747-763.

\section{NOTE}

1. $A^{\prime}$, like $d^{\prime}$, is an estimate of recognition sensitivity that is theoretically independent of the decision criterion. $A^{\prime}$ varies from 0 to 1 with .5 representing chance performance. $A^{\prime}$ is equivalent to percent correct on a two-alternative forced-choice recognition test. Donaldson (1993) has shown that $d^{\prime}$ is a slightly better measure when performance is unbiased, and that $A^{\prime}$ is a better measure when criterion changes occur. $B_{0}^{\prime \prime}$ is the measure of the decision criterion associated with $A^{\prime}$ and ranges from -1 to +1 . Positive values reflect conservative performance and negative values indicate liberal responding.

(Manuscript received May 26, 1998; revision accepted for publication March 19, 1999.) 